\title{
M-PSK System Performance in Multi-Channel Environments with MATLAB Simulink Models
}

\author{
${ }^{1}$ Zainab Faydhe Al-Azzawi, ${ }^{2}$ Fatima Faydhe AL-Azzawi and ${ }^{3}$ Sada Faydhe Al-Azzawi \\ ${ }^{1}$ Department of Computer Technology Engineering, AL-Mansour University College, \\ Baghdad, Iraq \\ ${ }^{2}$ Department of Electronic Technical, Institute of Technology, Middle Technical University, \\ Baghdad, Iraq \\ ${ }^{3}$ Department of Statistics, Measurement and Economic College, University of Kerbala, Kerbala, Iraq \\ zainab.faydh@muc.edu.iq
}

\begin{abstract}
PSK modulation approach is one of the most digital modulation methods used in communication systems recording to low transmitted power for a given probability of error than other digital modulation techniques. In this study PSK Model design and implemented using MATLAB Simulink and tested under multi-channel environment with BER improvement in each channel type, M-PSK Model examined under adjacent and co-channel interference by using two interfering signal. The model enables the modifying of the frequency offset and the power gain of each interferer and view the effects ona spectrum plot.
\end{abstract}

Key words: M-PSK, co-channel interference, adjacent interference, digital modulation, BER improvement, interfering signal

\section{INTRODUCTION}

PSK modulation approach is one of the most digital modulation methods used in communication systems recording to low transmitted power for a given probability of error than other digital modulation techniques as compared to ASK and FSK, PSK is less susceptible to errors than ASK while it requires/occupies the same bandwidth as ASK and more efficient use of bandwidth (higher data-rate) are possible, compared to FSK. Disadvantages of PSK over ASK and FSK is more complex signal detection/recovery process than in ASK and FSK (Simon and Alouini, 2000; Lee, 1986).

Owing to PSK's simplicity, particularly when compared with its competitor quadrature amplitude modulation, it is widely used in existing technologies. The wireless LAN standard, IEEE 802.11b-1999, uses a variety of different PSKs depending on the data rate required. At the basic rate of $1 \mathrm{Mbit} / \mathrm{sec}$, it uses DBPSK (differential BPSK) (John, 2008; Simon et al., 1995). To provide the extended rate of $2 \mathrm{Mbit} / \mathrm{sec}, \mathrm{DQPSK}$ is used. In reaching $5.5 \mathrm{Mbit} / \mathrm{sec}$ and the full rate of $11 \mathrm{Mbit} / \mathrm{sec}$, QPSK is employed but has to be coupled with complementary code keying. The higher-speed wireless LAN standard, IEEE 802.11g-2003, has eight data rates: 6, 9, 12, 18, 24, 36, 48 and $54 \mathrm{Mbit} / \mathrm{sec}$. The 6 and $9 \mathrm{Mbit} / \mathrm{sec}$ modes use
OFDM modulation where each sub-carrier is BPSK modulated. The 12 and $18 \mathrm{Mbit} / \mathrm{sec}$ modes use OFDM with QPSK. The fastest four modes use OFDM with forms of quadrature amplitude modulation (Odenwalder, 1976; Sklar and Ray, 2001).

Because of its simplicity, BPSK is appropriate for low-cost passive transmitters and is used in RFID standards such as ISO/IEC 14443 which has been adopted for biometric passports, credit cards such as American Express's express pay and many other applications (Sodhi and Sharma, 2010; Lyons, 2012). Bluetooth 2 will use DQPSK at its lower rate $(2 \mathrm{Mbit} / \mathrm{sec})$ and 8-DPSK at its higher rate $(3 \mathrm{Mbit} / \mathrm{sec})$ when the link between the two devices is sufficiently robust. Bluetooth 1 modulates with Gaussian minimum-shift keying, a binary scheme, so, either modulation choice in Version 2 will yield a higher data-rate. A similar technology, IEEE 802.15.4 (the wireless standard used by ZigBee) also relies on PSK using two frequency bands: $868-915 \mathrm{MHz}$ with BPSK and at $2.4 \mathrm{GHz}$ with OQPSK (Lyons, 2012; Vasudevan, 2017).

In this study, PSK system will be implemented in MATLAB Simulink and tested under AWGN, Rayleigh and Rician channels, BER performance improved in various channels, the effect of adjacent and co-channel interference on PSK model system illustrated with MATLAB Simulink Model.

Corresponding Author: Zainab Faydhe Al-Azzawi, Department of Computer Technology Engineering, AL-Mansour University College, Baghdad, Iraq, zainab.faydh@muc.edu.iq 


\section{MATERIALS AND METHODS}

PSK modulator: PSK modulator model design and implemented using MATLAB Simulink as shown in Fig. 1, input signal from signal generator block is upped using constant block then 1 and 0 'sec modulated with carrier 1 and 2, respectively as shown in Fig. 2 where all signals of PSK modulator illustrated.
PSK modulator and demodulator: PSK signal demodulated by PSK demodulator as shown in Fig. 3 where input signal recovered as in Fig. 4 where all demodulation signals illustrated.

PSK in-channel environments: PSK modulation system have been examined under multi-channel environments in term of BER in both theoretical and practical calculations

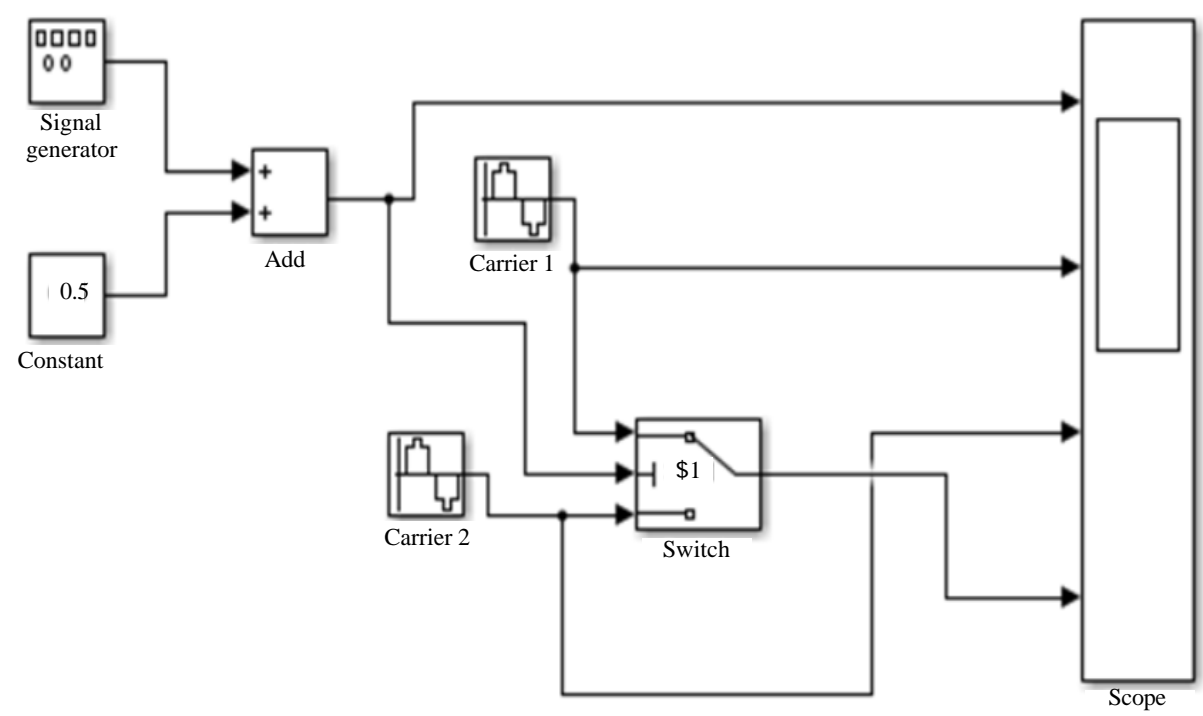

Fig. 1: PSK modulator model
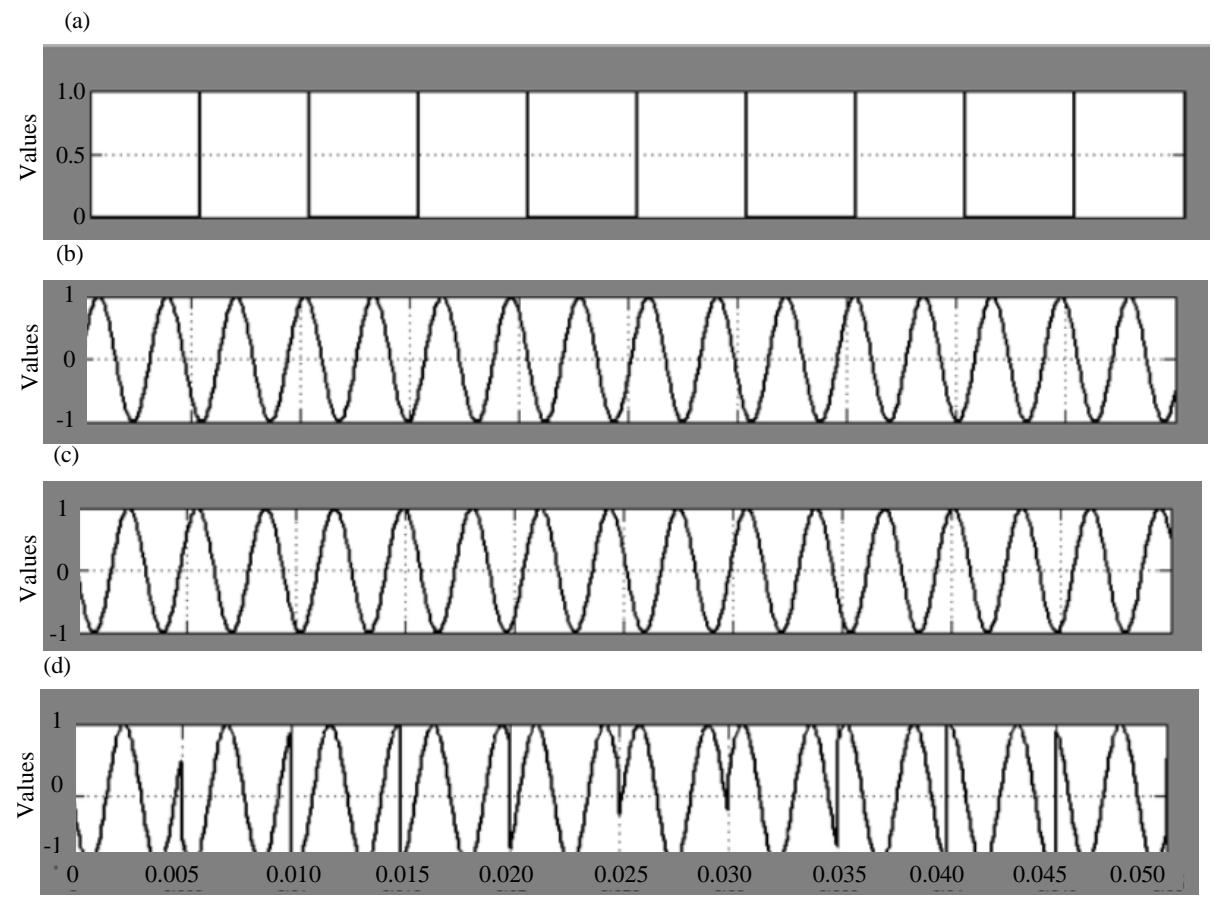

Signals

Fig. 2: a-d) PSK modulator signals: information, carrier 1 and 2, PSK signal 


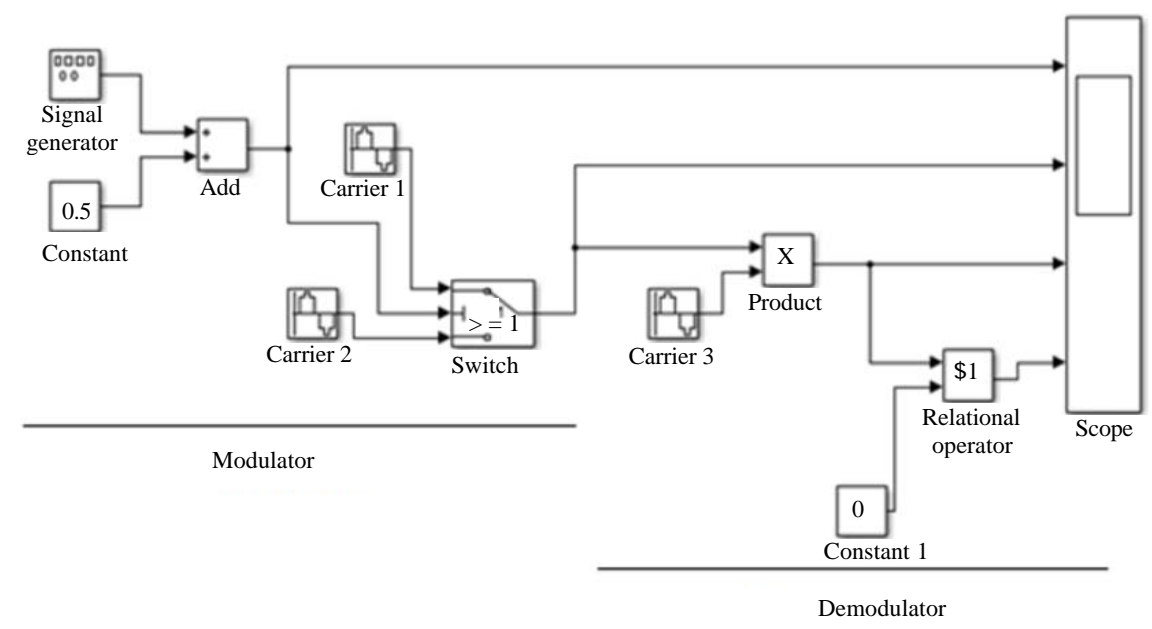

Fig. 3: PSK modulator and demodulator
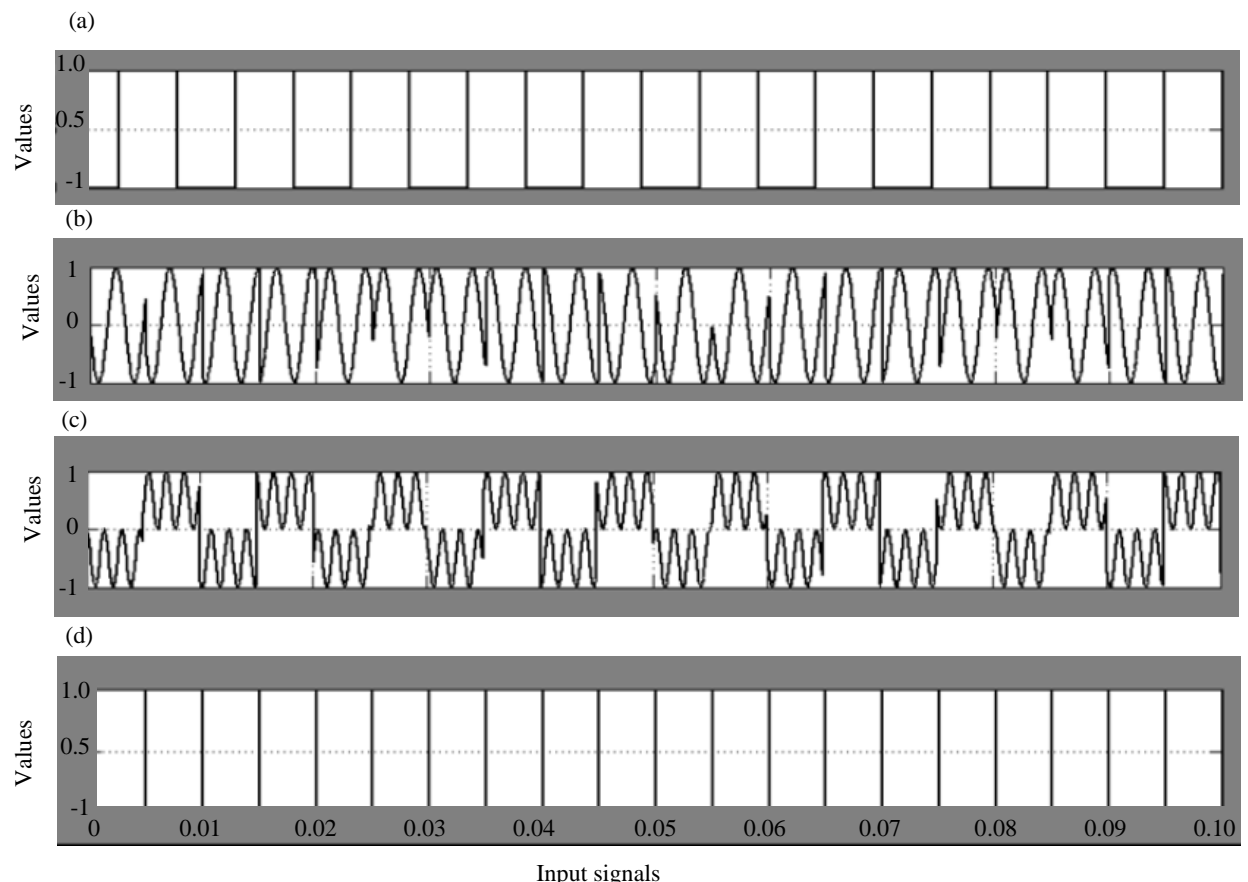

Fig. 4: a-d) PSK demodulator signals: information, PSK, after generation, recovered input signal

below theoretical equation of PSK system in AWGN, fading channels with improving method of decreasing BER in each channel.

PSK with multi order in AWGN: M-PSK under AWGN can be given in equation below (Simon and Alouini, 2000):

$$
\mathrm{P}_{\mathrm{S}}=\frac{1}{\pi} \int_{0}^{\frac{(\mathrm{Mi}-1)}{\mathrm{Mi}}} \operatorname{expi}\left(-\frac{\mathrm{kiE}_{\mathrm{b}}}{\mathrm{N}_{0}} \frac{\sin ^{2} \mathrm{i}\left[\frac{\pi}{\mathrm{Mi}}\right]}{\mathrm{i} \sin ^{2} \theta}\right) \mathrm{d} \theta
$$

Where:

$\mathrm{P}_{s} \quad=$ Symbol Error Rate (SER)

$\mathrm{P}_{\mathrm{b}}=$ Bit Error Rate (BER)

$\mathrm{Mi}=$ Size of modulation constellation

$\mathrm{Ki}=$ Numbery of bits per symbol $\rightarrow \mathrm{k}=\log _{2} \mathrm{M}$

$\mathrm{E}_{\mathrm{b}} / \mathrm{E}_{0}=$ Energy per bit-to-noise power-spectral-density ratio

$\theta=$ The phase angle from $-\pi / 2$ to $\pi / 2$

The following expression is very close but not strictly equal, to the exact BER (Simon and Alouini, 2000; Lee, 1986): 


$$
\mathrm{P}_{\mathrm{b}}=\frac{1}{\mathrm{k}}\left(\sum_{\mathrm{i}=1}^{\frac{\mathrm{i} M}{2}}\left(\mathrm{w}_{\mathrm{i}}^{\prime}\right) \mathrm{P}_{\mathrm{i}}\right)
$$

Where: $w_{i}^{\prime}=i w_{i}+i w_{M i}, i w_{\frac{M}{2}}^{\prime}=w_{\frac{M}{2}}, w_{i}$ is the Hamming weight of bits assigned to symbol $i$ and:

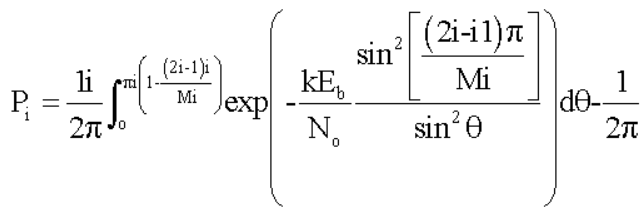

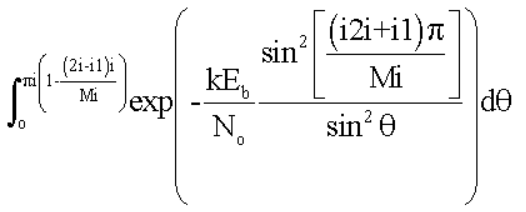

Convolutional coding: Specific notation for convolutional coding expressions: $\mathrm{d}_{\text {free }}$ is the free distance of the code and is the number of paths of distance $d$ from the all-zero path that merge with the all-zero path for the first time (Simon and Alouini, 2000; John, 2008):

$$
\mathrm{P}_{\mathrm{b}}<\sum_{\mathrm{d}=\mathrm{d}_{\text {fox }}}^{\infty} \mathrm{ia}_{\mathrm{d}} \mathrm{f}(\mathrm{id}) \mathrm{iP}_{2}(\text { idi })
$$

where:

$$
i P_{2}(d)=\sum_{k i=d i+1 / i 2}^{d i}\left(\begin{array}{cc}
d i \\
k i
\end{array}\right) P^{k}(i 1-i P)^{d-1 k}
$$

when, $d$ is odd and:

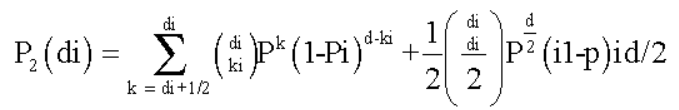

when, $d$ is even ( $p$ is the Bit Error Rate (BER) in an un coded AWGN channel). General linear block code (John, 2008; Simon et al., 1995):

$$
\begin{gathered}
\mathrm{P}_{\mathrm{b}} \leq \frac{\mathrm{li}}{\mathrm{N}} \sum_{\mathrm{m} i=t+1}^{\mathrm{N}}(\mathrm{mi}+\mathrm{t})\left(\begin{array}{c}
\mathrm{Ni} \\
\mathrm{mi}
\end{array}\right) \mathrm{P}^{\mathrm{m}}(1-\mathrm{pi})^{\mathrm{N}-\mathrm{mi}} \\
\mathrm{t}=\left|\frac{1}{2}\left(\mathrm{~d}_{\min }-1 \mathrm{i}\right)\right|
\end{gathered}
$$

Hamming code, Simon et al. (1995 and Odenwalder (1976):

$$
\mathrm{P}_{\mathrm{b}}=\frac{1}{\mathrm{~N}} \sum_{\mathrm{m}=2}^{\mathrm{N}} \mathrm{m}\left(\begin{array}{l}
\mathrm{N} \\
\mathrm{m}
\end{array}\right) \mathrm{Pi}^{\mathrm{m}}(1 \mathrm{i}-\mathrm{pi})^{\mathrm{iN}-\mathrm{m}}=\mathrm{ip}-\mathrm{ip}(\mathrm{i} 1-\mathrm{ip})^{\mathrm{N}-\mathrm{i}-1}
$$

Extended golay code, John (2008) and Simon et al. (1995):

$$
\mathrm{P}_{\mathrm{b}}=\frac{1}{24} \sum_{\mathrm{m}=2}^{24} \mathrm{~m}\left(\begin{array}{c}
24 \\
\mathrm{~m}
\end{array}\right) \mathrm{P}^{\mathrm{m}}(1-\mathrm{p})^{24-\mathrm{m}}
$$

where, $\beta_{\mathrm{m}}$ isi the average number of channel symbol errors that remain in corrected Ni-tuple when the channel caused m symbol errors (Simon et al., 1995). Reed-Solomon code with $\mathrm{Ni}=$ Qi-1 i $=\mathrm{i} 2^{\mathrm{q}}-\mathrm{i1}$ :

$$
P_{b}=\frac{i 2^{q-1}}{2^{q}-1} \frac{1}{N} \sum_{m=t+1}^{N} m\left(\begin{array}{l}
N \\
m
\end{array}\right)\left(P_{s}\right)^{m}\left(1-P_{s}\right)^{N-m}
$$

PSK in ray leigh fading channel: M-PSK under the rayleigh channel (Simon and Alouini, 2000; Lee, 1986):

$$
\begin{gathered}
\mathrm{P}_{s}=\frac{1}{\pi} \int_{0}^{(\mathrm{iM}-1) \pi / \mathrm{MM}} \prod_{1=1}^{\mathrm{Li}} \mathrm{M}_{\mathrm{\gamma}_{1}}\left(\frac{\operatorname{sini}^{2}\left(\frac{\mathrm{i} \pi}{\mathrm{iM}}\right)}{\sin ^{2} \theta}\right) d \theta \\
\mathrm{P}_{\mathrm{b}}=\frac{1}{\mathrm{k}}\left(\sum_{\mathrm{i}=\mathrm{i} 1}^{\mathrm{M} / 2}\left(\mathrm{w}_{\mathrm{i}}^{\prime}\right) \overline{\mathrm{P}}_{\mathrm{i}}\right)
\end{gathered}
$$

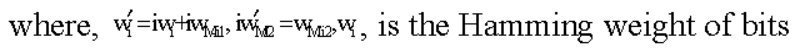
assigned to symbol $i$ and:

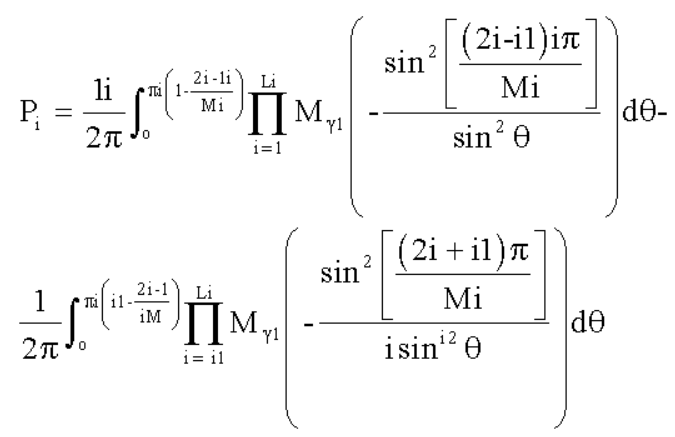

\section{RESULTS AND DISCUSSION}

Below practical results of PSK system testing in multi-channel in term of BER and improving method of each channel.

PSK with multi order in AWGN: Multi order of PSK system have been tested under AWGN channel as shown in Fig. 5 where the results show as PSK order increased $\mathrm{BER}$ of the system remain constant with increasing of input power reach to approximately $5 \mathrm{~dB}$. 


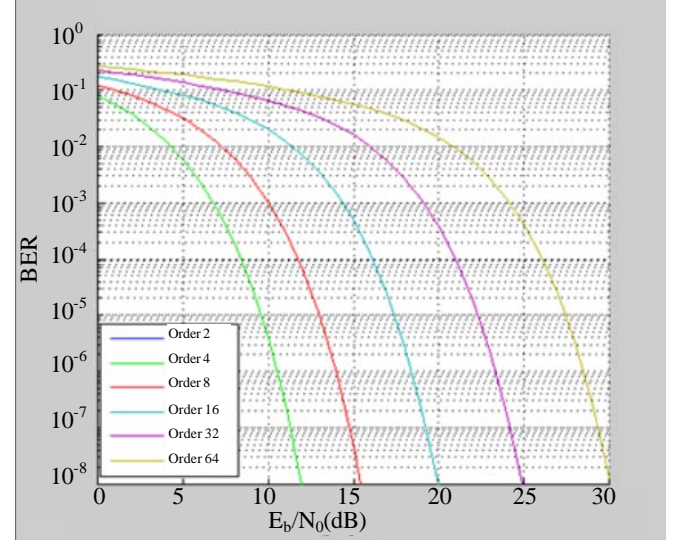

Fig. 5: PSK BER in AWGN channel with multi order

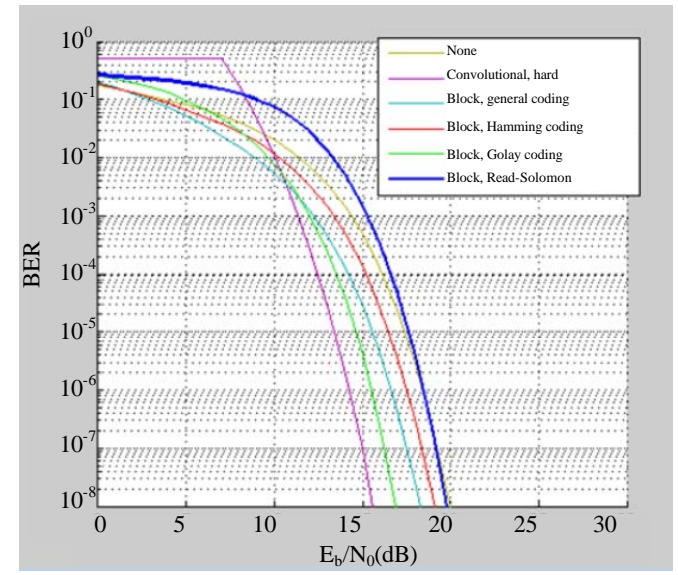

Fig. 6: PSK in AWGN channel with multi codes

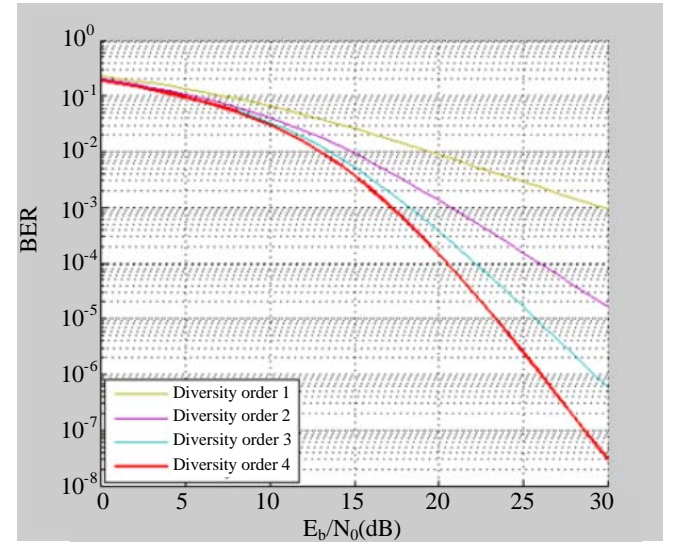

Fig. 7: PSK in Ray leigh fading channel

PSK with multi-channel coding in AWGN channel: Multi code used to improve BER of PSK system under AWGN channel, maximum improving with convolutional code

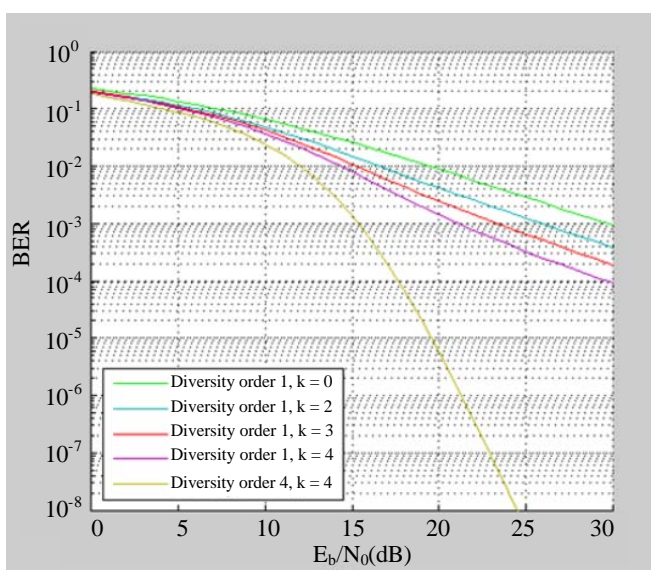

Fig. 8: PSK in Racian fading channel

where BER improved with gain $4.5 \mathrm{~dB}$ in $\mathrm{E}_{\mathrm{b}} / \mathrm{N}_{0}$, all other codes used for improving system performance below this percentage as shown in Fig. 6.

PSK in Ray leigh fading channel: PSK system is tested under ray-leigh channel as shown in Fig. 7 as improving the performance of the system under this type of channels increasing diversity order used. From figure below as increasing diversty order from 1-4 the gain in $E_{0} / N_{0}$ reached to $12.5 \mathrm{~dB}$ in $10^{-3} \mathrm{BER}$.

PSK in Racian fading channel: Raicing fayding channell have been tested with PSK system as shown in Fig. 8 where the results show as the diversity order increased and the $\mathrm{k}$ factor which is the ratio of energy in the specular component to the energy in the diffuse component, BER decreased with gain equal to $15 \mathrm{~dB}$ when diversity order increased from 1-4 and $\mathrm{k}$ factor increased from 0-4.

Adjacent and co-channel interference system: This model shows the effects of adjacent and co-channel interference on a PSK modulated signal as shown in Fig. 9. The model includes two interferers, interferer 1 and 2 as shown in Fig. 10 and 11 . The model enables the modification of the frequency offset and the power gain of each interferer and views the effects on a spectrum plot (Fig. 12).

The communication system in this example includes these components. A transmitter which creates a PSK modulated signal and applies a square root raised cosine filter. The result is the original signal to which interference is added. Two interferers, interferer 1 and 2, each of which is similar to the transmitted signal but has 


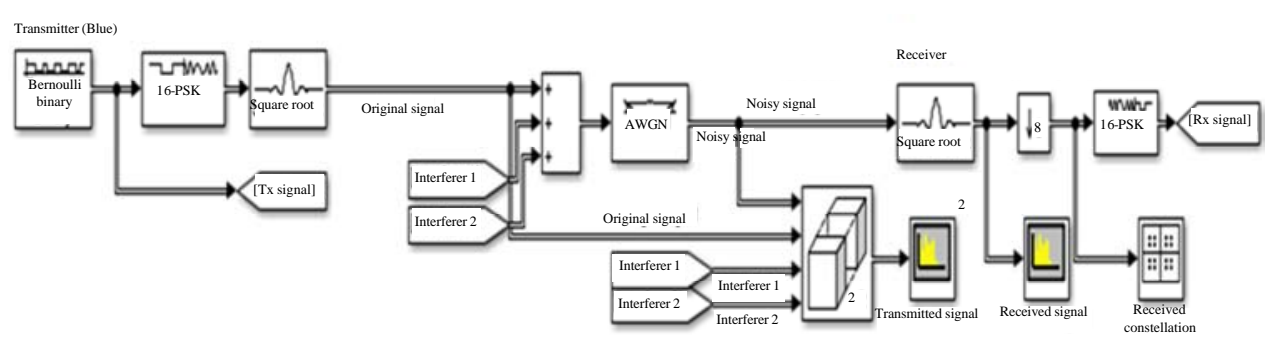

Fig. 9: Adjacent and co-channel interference system Simulink Model

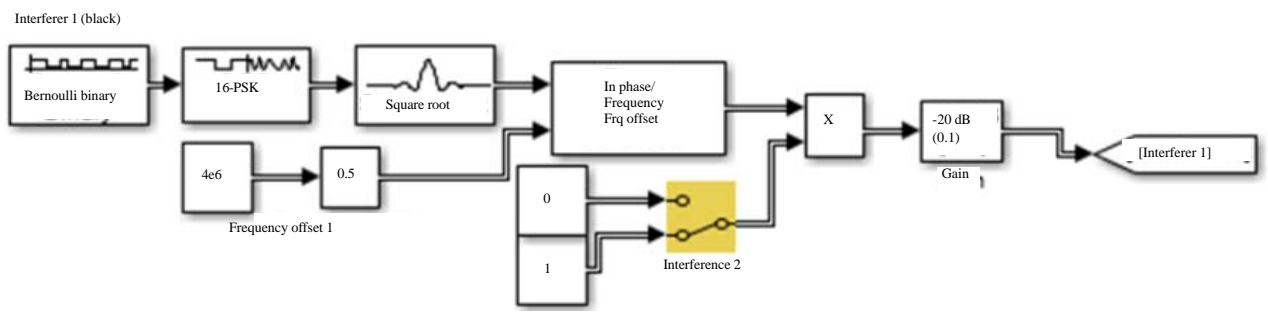

Fig. 10: Interferer 1 Simulink Model

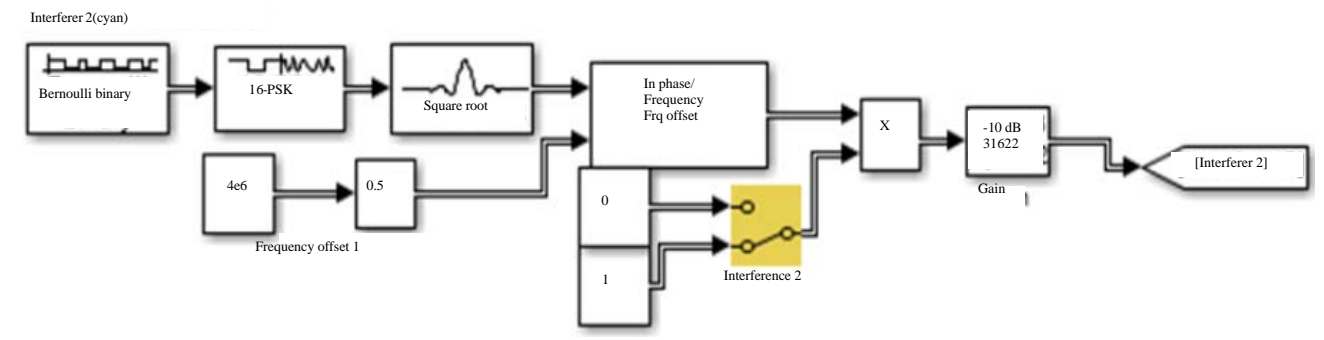

Fig. 11: Interferer 2 Simulink Model

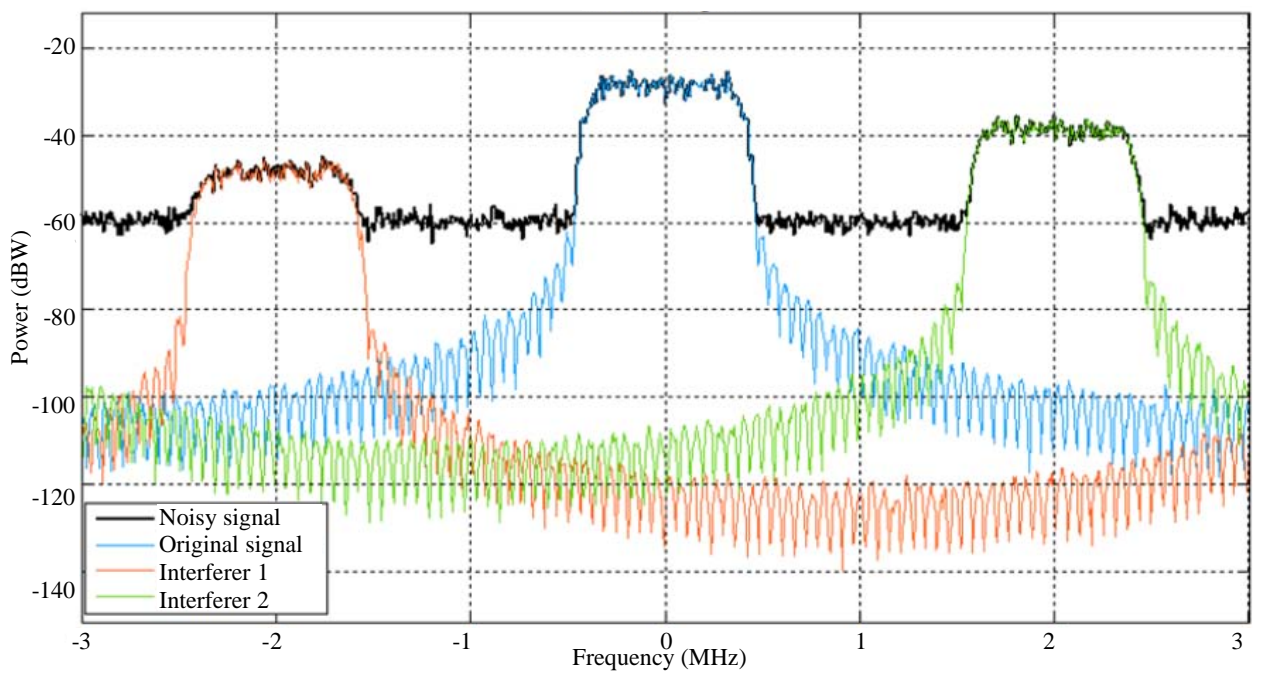

Fig. 12: The spectra of the original and interfering signals and the noisy transmitted signal

a modifiable frequency offset and power gain. A sum block in the model adds the two interfering signals to the original signal. By default, both interferers are active, however, a deactivation one or both interferers as described in experimenting as in Fig. 10 and 11 . 


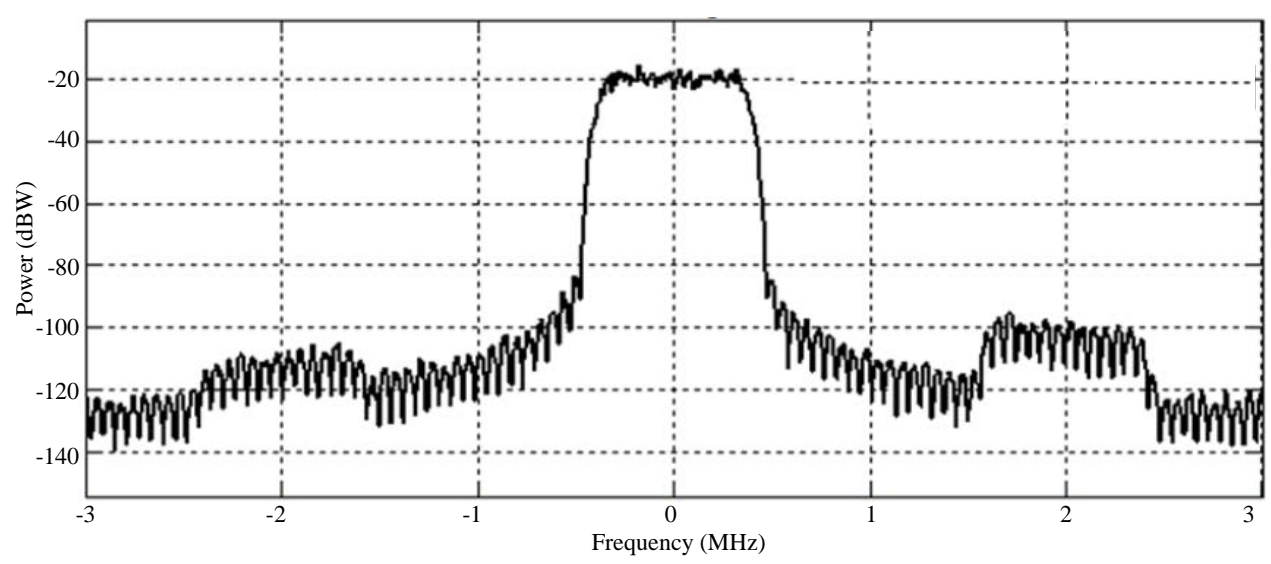

Fig. 13: The spectrum of the received signal; Raised cosin receiver filter

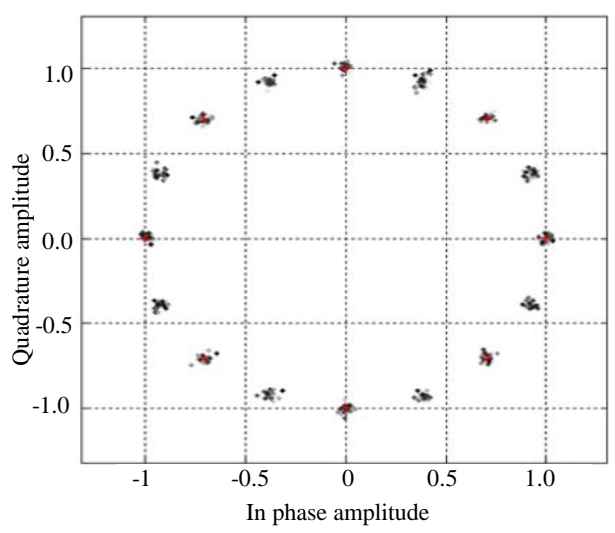

Fig. 14: A scatter plot of the received signal constellations

An AWGN channel: A receiver which filters, down samples and demodulates the received signal. The spectra of the original and interfering signals and the noisy transmitted signal is shown in Fig. 12 where the blue signal is the original signal and the green, red are the interferer signals 1 and 2, the black one is the noise signal. The spectrum of the received signal is shown in Fig. 13 where difference between main lobe and side lobes 80 $\mathrm{dBW}$ as shown in Fig. 13, using the square root filter and down sampling at the receiver reduces the effect of interferer signals on recovered signal.

A scatter plot of the received signal constellations is shown in Fig. 14. The 16 PSK constellation with Gray mapping can be as shown where, 16-i PSK constellation is shown to the right where each phase is separated by $360^{\circ} / 16=22.5^{\circ}$. To demodulate any type of PSK, a receiver must determine the phase of the received symbol. For 16PSK, the receiver must determine the phase within $\pm 11.25^{\circ}$, since, the phases are separated by $22.5^{\circ}$. As more phases are used in PSK, the symbols are closer together which makes it easier for the receiver to make bit errors but of course, the advantage of more symbols is a narrower bandwidth, if the bitrate is held constant. There is a way to use more symbols in modulation while reducing the chances of making bit errors by using symbols that have different amplitudes and phases.

\section{CONCLUSION}

M-PSK Model have been design with MATLAB Simulink modulator and demodulator and tested under multichannel environments, from the results BER of the M-PSK system under AWGN can be reduces by using convolutional code and block code (hamming, Golay, Reed-solomon) by gain in $\mathrm{E}_{\mathrm{b}} / \mathrm{N}_{0} 5 \mathrm{dBW}$ when using convolution code while when increasing modulation order BER increased, M-PSK under Rayleigh channel performance can be improved by increasing diversity order with gain equal to $12 \mathrm{dBW}$ when diversity order increased from 1-4, M-PSK under Rician fading channel performance can be improved by increasing diversity order and $\mathrm{K}$ factor with gain equal to $15 \mathrm{dBW}$ when diversity order 4 and $\mathrm{K}$ factor 4, 16-PSK transmitter and receiver is implemented with MATLAB Simulink with two channel interferer with good performance depending on the spectrum and a scatter plot of the received signal constellations.

\section{REFERENCES}

John, G.P., 2008. Digital Communications. 5th Edn., McGraw-Hill, New York, USA., ISBN:9780071263788, Pages: 1150.

Lee, P., 1986. Computation of the bit error rate of coherent M-ary PSK with gray code bit mapping. IEEE. Trans. Commun., 34: 488-419. 
Lyons, R.G., 2012. Streamlining Digital Signal Processing: A Tricks of the Trade Guidebook. 2nd Edn., Wiley Publishing Company, Hoboken, New Jersey, USA., ISBN:9781118278383, Pages: 496.

Odenwalder, J.P., 1976. Error Control Coding Handbook: Final Report. Linkabit Corporation, San Diego, CA. USA., pp: 213.

Simon, M.K. and M.S. Alouini, 2000. Digital Communication over Fading Channels: A Unified Approach to Performance Analysis. 1st Edn., John Wiley \& Sons, Hoboken, New Jersey, USA., ISBN:9780471317791, Pages: 544.

Simon, M.K., S.M. Hinedi and W.C. Lindsey, 1995. Digital Communication Techniques: Signal Design and Detection. PTR Prentice Hall, Upper Saddle River, New Jersey, USA., ISBN: 9780132006101 , Pages: 888.
Sklar, B. and P.K. Ray, 2001. Digital Communications Fundamentals and Applications. 2nd Edn., Pearson Education, Delhi, Chennai, India, ISBN: 978-81317-2092-9, Pages: 1139.

Sodhi, G.K. and K.K. Sharma, 2010. Performance evaluation of 8 PSK and 16 PSK using reed-solomon codes. Proceedings of the International Conference on Methods and Models in Science and Technology (ICM2ST-10), December 25-26, 2010, American Institute of Physics, Chandrigarh, India, ISBN:978-0-7354-0879-1, pp: 365-368,

Vasudevan, K., 2017. Digital Communications and Signal Processing. Indian Institute of Technology, Kanpur, India, Pages: $461 . \mathrm{s}$ 